\title{
Possible effects on Earth's climate due to reduced atmospheric ionization by GCR during Forbush Decreases
}

\author{
Williamary Portugal ${ }^{1}$, Ezequiel Echer ${ }^{1}$, Mariza Pereira de Souza \\ Echer $^{1}$, and Alessandra Abe Pacini ${ }^{2}$ \\ ${ }^{1}$ INPE - National Institute for Space Research \\ email: williamary.portugal@inpe.br \\ ${ }^{2}$ Johns Hopkins University/Applied Physics Lab.
}

\begin{abstract}
This work presents the first results of a study about possible effects on the surface temperature during short periods of lower fluxes of Galactic Cosmic Rays at Earth, called Forbush Decreases. There is a hypothesis that the Galactic Cosmic Ray flux decreases cause changes on the physical-chemical properties of the atmosphere. We have conducted a study to investigate these possible effects on several latitudinal regions, around the ten strongest FDs occurred from 1987 to 2015 . We have found a possible increase on the surface temperature at middle and high latitudes during the occurence of these events.
\end{abstract}

Keywords. Cosmic rays, solar activity, Forbush Decreases, solar-terrestrial relations, surface temperature.

\section{Introduction}

The possible effects of Galactic Cosmic Rays (GCR) on the physical - chemical atmospheric processes with influence on the surface temperature and consequently on the Earth's climate, has been widely studied recently (Svensmark \& Friis - Christensen 1997, Marsh \& Svensmark 2000, Marsh \& Svensmark 2000a, Usoskin et al. 2004, Svensmark, Bondo \& Svensmark 2009, Dragic et al. 2011, Marsh \& Svensmark 2011 and Svensmark, Enghoff \& Svensmark 2012). The hypothesis is that the ions present on the atmosphere, resulted from the induced ionization by GCR, can be enhanced by ion-ion or by ionmolecule combination, increasing the total number of aerossols (Usoskin \& Kovaltsov 2008). Since some ions / aerossols can behave like cloud condensation nuclei, it is known that the presence of ions in the troposphere, that vary with the GCR flux variation, may change the water vapor condensation patterns (Usoskin \& Kovaltsov 2008).

Some works have investigated the atmospheric parameter variation during the sporadic periods of lower GCR flux, called Forbush Decreases (FD) (Svensmark, Bondo \& Svensmark 2009, Dragic et al. 2011 and Svensmark, Enghoff \& Svensmark 2012). FDs are events characterized by a lower flux of GCR particles reaching the atmosphere, that occur mainly due to the passage of interplanetary remnants of Coronal Mass Ejections (CMEs) on the Earth (Cane 2000). So, if more energetic particles are impinging on the Earth's atmosphere (lower solar magnetic activity) leading to more ionization, it is possible that the presence of a lower GCR flux, will lead to atmospheric changes too. Then, we have investigated the possible effects of solar variability related to surface temperature on several global regions, including high and middle latitude stations of the two hemispheres (Northern and Southern), around the ten strongest FDs occurred from 1987 to 2015. 
Table 1. The strongest FD events from 1987 to 2015, the 0 day, the periods analised, the decrease intensity (\%) considering Oulu Neutron Monitor data, solar cycle and the solar polarity of the periods investiged.

\begin{tabular}{|c|c|c|c|c|c|c|c|}
\hline FD & $\begin{array}{c}\text { Day } 0 \text { and } \\
\text { Period Analised }\end{array}$ & $\begin{array}{c}\text { Intensity } \\
(\%)\end{array}$ & \begin{tabular}{|l} 
Solar Cycle \\
and Polarity
\end{tabular} & FD & $\mid \begin{array}{c}\text { Day } 0 \text { and } \\
\text { Period Analised }\end{array}$ & $\mid \begin{array}{c}\text { Intensity } \\
(\%)\end{array}$ & \begin{tabular}{|l} 
Solar Cycle \\
and Polarity
\end{tabular} \\
\hline 1 & $\begin{array}{c}\text { Oct. } 31,2003 \\
(10 / 26 \text { to } 11 / 10)\end{array}$ & 3 & $\begin{array}{l}\text { Cycle } \\
\quad \mathrm{A}>\end{array}$ & 6 & $\mid \begin{array}{c}\text { Jul. } 27,2004 \\
(07 / 22 \text { to } 08 / 06)\end{array}$ & 15.27 & $\begin{array}{r}\text { Cycle } \\
\mathrm{A}\end{array}$ \\
\hline 2 & $\begin{array}{c}\text { March } 24,1991 \\
(03 / 19 \text { to } 04 / 03)\end{array}$ & 22.00 & $\begin{array}{r}\text { Cycle } \\
\text { A }<\end{array}$ & 7 & $\mid \begin{array}{r}\text { Nov. } \\
(11 / 25\end{array}$ & 14.73 & $\begin{array}{r}\text { Cycle } \\
\text { A }\end{array}$ \\
\hline 3 & $\begin{array}{c}\text { Oct. } 29,1991 \\
(10 / 24 \text { to } 11 / 08)\end{array}$ & 20.20 & $\begin{array}{c}\text { Cycle } \# 22 \\
\mathrm{~A}<0\end{array}$ & 8 & $\mid \begin{array}{c}\text { Sep. } 13,2005 \\
(09 / 08 \text { to 09/23) }\end{array}$ & 14.35 & $\begin{array}{c}\text { Cycle } \# 23 \\
A>0\end{array}$ \\
\hline 4 & $\begin{array}{c}\text { Mar. } 13,1989 \\
(03 / 08 \text { to } 03 / 23)\end{array}$ & 17.44 & $\begin{array}{c}\text { Cycle } \# 22 \\
\mathrm{~A}<0\end{array}$ & 9 & $\mid \begin{array}{c}\text { Nov. } 10,2004 \\
(11 / 05 \text { to } 11 / 20)\end{array}$ & 13.00 & $\begin{array}{c}\text { Cycle \#23 } \\
A>0\end{array}$ \\
\hline 5 & $\begin{array}{c}\text { Mar. } 9,2012 \\
(03 / 04 \text { to } 03 / 19)\end{array}$ & 15.60 & $\begin{array}{c}\text { Cycle } \# 24 \\
\mathrm{~A}<0\end{array}$ & 10 & $\begin{array}{c}\text { Jun. } 25,2015 \\
(06 / 20 \text { to } 07 / 05)\end{array}$ & 11.00 & $\begin{array}{c}\text { Cycle } \# 24 \\
\mathrm{~A}<0\end{array}$ \\
\hline
\end{tabular}

\section{Methodology}

Using GCR data collected from Oulu neutron monitor (Lat: $65.01^{0}$; Long: $25.51^{0}$ ) where the local vertical geomagnetic cutoff rigidity $\left(\mathrm{P}_{\mathrm{c}}\right)$ is about $0.8 \mathrm{GV}$ and surface temperature data obtained from NOAA - National Oceanic Atmospheric Administration / GSOD - Global Surface Summary of the Day, we constructed time series of surface temperature daily mean from ten meteorological stations of high $\left(60^{0}-70^{0}\right)$ and of middle $\left(40^{0}-50^{0}\right)$ latitudes, of Northern and Southern Hemispheres, for a period of fifteen days around the ten strongest FD that occurred from 1987 to 2015 (Table 1). We have used five days before and ten days after the FD day - day 0, characterized by the day with the lowest flux of GCR, measured by a neutron monitor station. A superposed epoch analysis was performed considering the surface temperature daily mean of the meteorological stations of each latitude range of each hemisphere. Here we have investigated only the FD events not related to the occurrence of Ground Level Enhancement events, or GLEs.

\section{Preliminary Results and Discussion}

In this work we are showing the preliminary results on the temperatute variation during FD events at high and middle latitudes of the two hemispheres (Northern and Southern). Figure 1 suggests that there was an increase of the surface temperature during the occurence of FD events, reaching its maximum value some days after the 0 day. This delay of 3 to 6 days, between the FD events and the response in an atmospheric parameter, is found also by other works (e.g: Svensmark, Bondo \& Svensmark 2009 and Svensmark, Enghoff \& Svensmark 2012). This might indicate that there is a connection between GCR decrease and some changes on the atmosphere parameters, such as: aerossols, cloud cover, cloud microphysics and temperature (e.g.: Svensmark, Bondo \& Svensmark 2009, Dragic et al. 20112011 and Svensmark, Enghoff \& Svensmark 2012). A possible mechanism could be by effects of lower ionization on the chemical-physical atmospheric conditions due to lower GCR flux, that could lead to less aerossols, less cloud cover and consequently to the increase of solar irradiance reaching the surface, leading to warming / surface temperature increase. In future works we will investigate these effects on the low latitude region and the difference between the surface temperature on the same regions during the occurrence of FD and during normal periods, represented by 1987, 1996 and 

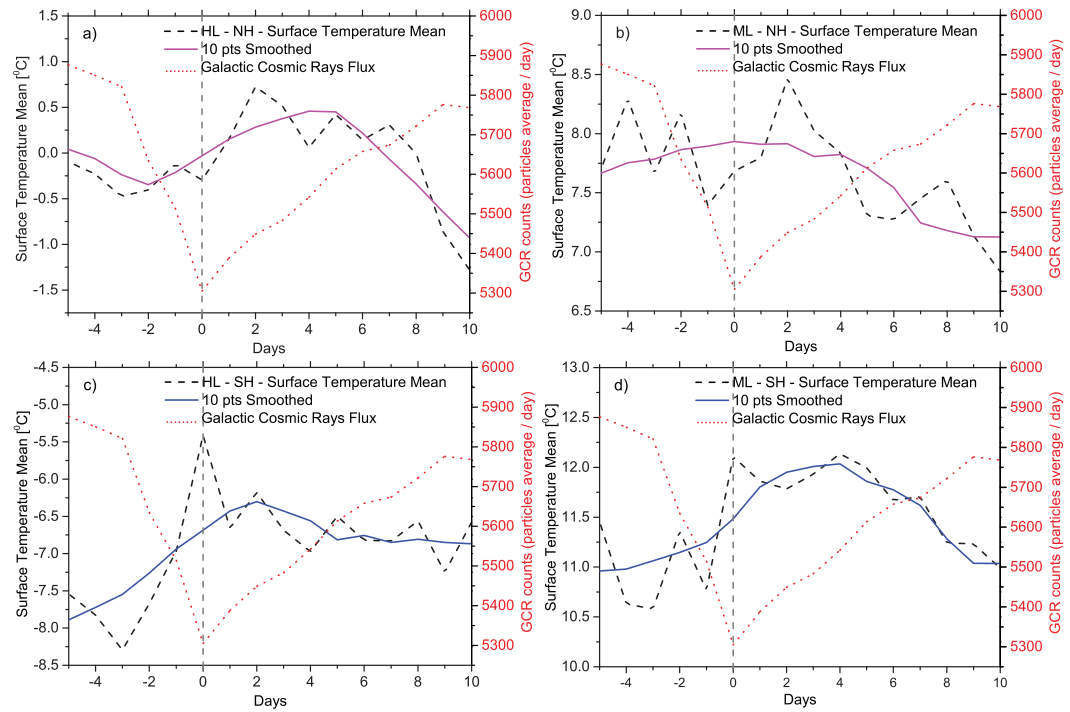

Figure 1. Superposed epoch analysis of surface temperature daily means of ten meteorological stations of diferent regions (black dashed line) during the ten strongest FD events: a) high latitude of Northern Hemisphere; b) middle latitude of Northern Hemisphere; c) high latitude of Southern Hemisphere; d) middle latitude of Southern Hemisphere. The continuous lines (pink and blue) represent the surface temperature daily mean data smoothed by 10 points. The red dot lines are representing the superposed epochs of GCR Flux from Oulu Neutron Monitor data and the grey vertical dashed line indicates the 0 day of FD. HL: High Latitude; ML: Middle Latitude; NH: North Hemisphere; SH: South Hemisphere.

2008 years (minimum solar periods). The final goal of this study is to understand the effects of the GCR on the surface temperature and the statistical significance of these effects in several global regions, in short and long time scales.

\section{Acknowledgements}

The authors would like to thanks for CAPES, INPE and Ezequiel Echer - CNPQ/PQ (302583/2015-7).

\section{References}

Cane, H. V. 2000, Space Sci. Revs, 93, 55

Dragić, A., Aničin, I., Banjanać, R., Udovičić, V., Joković, D., Maletić, D., \& Puzović, J. 2011, ApESSS, 7, 315

Marsh, N. \& Svensmark, H. 2000, Space Sci. Revs, 94, 215

Marsh, N. \& Svensmark, H. 2000a, Phys. Rev. Lett., 85, 5004

Svensmark, H. \& Friis - Christensen, E. 1997, Journal of Atmospheric and Solar - Terrestrial Physics, 59, 1225

Svensmark, H. \& Bondo, T, Svensmark, J. 2009, Geophysical Research Letters, 36, L 15101, DOI 10.1029/2009GL038429

Svensmark, J., Enghoff, M. B., \& Svensmark, H. 2012, Atmos. Chem. Phys. Discuss., 12, 3595

Usoskin, I. G., Marsh, N., Kovaltsov, G. A., Mursula, K., \& Gladysheva, O. G. 2004, Geophysical Research Letters, 31, L16109

Usoskin, 1. G. \& Kovaltsov, G. A. 2008, C. R. Geoscience, 340, 441 